\title{
How Do Flexibility I-Deals Relate to Work Performance? Exploring the Roles of Family Performance and Organizational Context
}

\section{Mireia Las Heras}

Assistant Professor of Work and Organizational Psychology, IESE Business School, Spain E-Mail: mlasheras@iese.edu

\section{Yasin Rofcanin (corresponding author)}

Lecturer in Organizational Behavior and Human Resource Management

University of Essex, Essex Business School, the UK

E-Mail: yasin.rofcanin@essex.ac.uk

\section{P. Matthijs Bal}

Professor of Responsible Management

Lincoln International Business School

University of Lincoln, Lincoln, UK

Email: $\underline{\text { mbal@lincoln.ac.uk }}$

\author{
Jakob Stollberger \\ Research Fellow \\ Jubilee Centre for Character and Virtues \\ University of Birmingham, the UK \\ E-mail: j.stollberger@bham.ac.uk
}

Manuscript Accepted for Publication in Journal of Organizational Behavior 


\title{
How do flexibility i-deals relate to work performance?
}

\section{Exploring the roles of family performance and organizational context}

\begin{abstract}
Drawing on the work-home resources (W-HR) model and conservation of resources (COR) theory, in this study we explore how flexibility i-deals relate to employees' work performance through their family performance. In line with the W-HR model, we introduce two contextual conditions to explain when our proposed associations may unfold. One is a facilitator: perceived organizational support (POS); and the other is a stressor: perceived hindering work demands. The results of a matched sample of employees and their supervisors working in two companies in El Salvador support our hypotheses. Our findings show that the benefits of flexibility i-deals to the work domain (i.e., work performance) extend only through the family domain (i.e., family performance). Our findings also emphasize that flexibility i-deals do not unfold in a dyadic vacuum: For employee who perceive organizational support to be higher, the association between flexibility i-deals and family performance is stronger, while for employees who perceive hindering work demands to be lower, the association between family performance and employee work performance is also stronger. We contribute to i-deals research by a) exploring a relevant mechanism through which flexibility i-deals influence work performance; b) integrating the role of social context to emphasize the social aspects of i-deals; and c) enriching the i-deals literature by introducing a resource perspective.
\end{abstract}

Key words: I-deals, family performance, work performance, POS, hindering work demands. 


\section{Introduction}

Employees increasingly desire a more personalized treatment at work (Glassner \& Keune, 2012; Greenhaus, Callanan, \& Godshalk, 2010; Guest \& Rodrigues, 2015), and thus employers can no longer rely on a one-size-fits-all approach to human resource management (HRM) practices. One strategy to cater the new desire for customization is to provide employees with idiosyncratic deals (ideals), which are personalized employment conditions of a non-standard nature negotiated between an employee and an employer (Rousseau, Ho, \& Greenberg, 2006). Employees tend to negotiate i-deals to improve their work and non-work lives, while employers tend to grant i-deals to employees to enhance their work performance (Rousseau, 2005). However, to our knowledge, it has not been yet proved that i-deals are mutually beneficial for employees and employers. It is important to investigate the outcomes of i-deals from the perspectives of both employees and employers, as i-deals are costly (Bal \& Rousseau, 2015), and employers may refrain from implementing i-deals if they perceive no advantages. While i-deals offer employees opportunities to experience a better fit with their jobs, it is important to understand the processes that lead to benefits for both employees and employers as a result of i-deal negotiations. The main goal of this paper is to explore the mechanisms and contextual conditions under which i-deals produce positive outcomes for both employee and employer.

We ground this study on Ten Brummelhuis \& Bakker's (2012) work-home resources model (W-HR), which builds on Hobfoll's (1989) conservation of resources (COR) theory. The W-HR model explains how work and family life may either conflict or enrich each other. Drawing on the W-HR model, which integrates resource enrichment and conflict concepts into the work-family interface (Ten Brummelhuis \& Bakker, 2012), our first goal is to explain how and why flexibility i-deals - a particular form of i-deal aiming to address employees' non-work demands (Bal \& Rousseau, 2015) contribute to employees' work performance. In integrating the inter-role enrichment perspective, we argue that flexibility i-deals generate further resources at home, such as spending more time with family or taking care of children during the day, thereby improving family performance. Enhanced family performance, in turn, is expected to enrich employees' engagement at work, leading to improved work performance. Our focus on family performance provides a better understanding of 
why previous research on the association between flexibility i-deals and work performance has produced inconsistent results (e.g., Hornung, Rousseau, \& Glaser, 2009) or, at best, weak effect sizes (Bal, De Jong, Jansen, \& Bakker, 2012). Thus, the first contribution of this study is our focus on subordinates' family performance as mechanism explaining how and why flexibility i-deals might influence subordinates' work performance. In using the W-HR Model, we also bring a resource perspective to the i-deals literature, which to date has tended to adopt social exchange theory (Liao et al., 2016) while leaving other theoretical perspectives unexplored (Conway \& Coyle-Shapiro, 2015).

Our second goal is to investigate contextual conditions that explain how the relationship between flexibility i-deals and employees' non-work and work outcomes may vary. A focus on contextual factors is important for the i-deals literature because, according to Rousseau (2005), contextual organizational factors affect the extent to which i-deals benefit focal employees and contribute to the functioning of employers. Nevertheless, researchers have so far paid little attention to the role of employees' work environment in exploring the effects of i-deals on performance (see Bal et al., 2012 for an exception). This may help explain the weak and inconsistent findings of studies that have investigated i-deal outcomes (e.g., Hornung et al., 2009).

To start filling this gap, we integrate one resource, perceived organization support (POS), and one demand, perceived hindering work demands, from the W-HR model. We argue that the association between flexibility i-deals and family performance may depend on employees' perceptions of the supportiveness of the organization (Bal, Kleef, \& Jansen, 2015; Eisenberger, Huntington, Hutchison \& Sowa, 1986). Since i-deals are personalized working conditions given to a focal employee, other members of the organization may both witness and interpret these deals (Greenberg et al., 2004). Thus, we argue that POS is a meaningful characteristic of the overall work environment that may offset the potential ramifications of using flexibility i deals. We further argue that higher (lower) levels of perceived hindering work demands are more (less) likely to create a conflict between home and work performance (Peeters, de Jonge, Janssen, \& Van der Linden, 2004; Tadic, Bakker, \& Oerlemans, 2015), preventing the transfer of benefits arising from the use of flexibility i deals from home to the work domain. 
Thus, the main contribution of our study lies in providing an overall model to guide exploration of how and when flexibility i-deals are associated with non-work and work domains. We use one mechanism (family performance) and two contextual conditions (POS and perceived hindering work demands) from the W-HR model to provide an overall picture of the relationships of flexibility i-deals with family and work performance. This is crucial, since i-deals are increasingly being used as strategic individualized HRM tools to enhance employees' performance in work and non-work domains (Bal et al., 2012; Ng \& Feldman, 2012).

Insert Figure 1 Here

\section{Theoretical overview}

\section{I-deals theory and related constructs}

I-deals are defined as "voluntary, personalized agreements of a non-standard nature negotiated between individual employees and their employers regarding terms that benefit each party" (Rousseau, 2005, p.23). Three defining features of i-deals are that they are negotiated individually, that they are intended to benefit both employee and employer, and that they vary in terms of scope (Liao et al., 2016). In terms of the content of i-deals, previous research has shown that the two most common types of i-deal are flexibility i-deals and development i-deals ( $\mathrm{Ng} \&$ Lucianetti, 2016; Rousseau, Hornung \& Kim, 2009). In this study, we focus on flexibility i-deals to explore the extent to which the benefits of such deals may extend to family and work domains. Flexibility i-deals involve individualized flexibility regarding the timing and location of work (Hornung, Rousseau, Glaser, Angerer, \& Weigl, 2010; Rosen, Slater, Chang, \& Johnson, 2013). Working partly away from the office and having nonstandard work shifts are examples of flexibility i-deals (Hornung et al., 2009; Vidyarthi, Chaudhry, Anand, \& Liden, 2014). 
We note that while flexibility i-deals are similar to flexible work practices (FWPs), they differ in important respects. One aspect is that FWPs are established and formal policies that employers make available to all employees (Allen, Johnson, Kiburz, \& Shockley, 2013; Leslie, Manchester, Park, \& Mehng, 2012), whereas i-deals refer to the discretionary actions of decision makers, usually managers or HR departments, regarding individual employees (Rousseau et al., 2006). Another difference is that FWPs are defined by procedures or policies; hence, the content of FWPs is shaped by pre-existing formal procedures (Allen et al., 2013). In contrast, i-deals are individually negotiated, and thus result from negotiations between specific employees and managers (Rousseau, 2005). We also note that i-deals are not written and formal HR policies and practices that managers implement; rather they result from a negotiation process that individuals initiate with their supervisors to address their personal work needs and preferences. Hence, i-deals do not (still) constitute policies during the period they are negotiated but they might turn into formal policies and practices following a successful negotiation process (Rofcanin, 2016).

Flexibility i-deals are also similar to family supportive supervisor behaviors (i.e., FSSBs) which are defined as "behaviors exhibited by supervisors that are supportive of families" (Hammer, Kossek, Yragui, Bodner, \& Hanson, 2009, p. 838). However, while these behaviors capture the extent to which supervisors offer emotional support to their subordinates, act as role models, and implement creative work-family management policies for all of their subordinates (Hammer, Kossek, Zimmerman, \& Daniels, 2007); flexibility i-deals are aimed at addressing a focal employees' work needs regarding location and schedule which is not necessarily confined to his or her family domain (Rofcanin, 2016).

\section{COR theory and the W-HR model in relation to i-deals}

The basic tenet of COR theory is that people attempt to obtain, retain and protect resources, and that stress occurs when people risk losing or actually lose resources (Hobfoll, 1989). According to COR theory, resources may be objects (e.g., a house), personal characteristics (e.g., health), conditions (e.g., marital status), energies (e.g., time) or support (e.g., love) that a person values. This theory 
suggests that the possession of resources leads to the generation of other resources within (or between) domains, referred to as the gain spiral (or enrichment). Furthermore, individuals with more resources tend to invest in obtaining more resources. Finally, people with more resources are better equipped to deal with stressful situations, and resource loss affects them less negatively. In a nutshell, COR theory is built on two basic assumptions: the gain spiral (or enrichment), in which resources accumulate within or between domains and lead to more resources, and the loss spiral (or conflict), in which resources are depleted and lost (Hobfoll, 1989, 2002).

Building on these assumptions of COR theory, the W-HR model integrates the enrichment and conflict concepts specifically into the work-home interface. This model elucidates the mechanisms through which resources gained in one domain (work or family) may relate to effective functioning in both the same and the other domain (Ten Brummelhuis \& Bakker, 2012). In explaining enrichment, the W-HR model distinguishes between types of resource depending on their origin (contextual versus personal resources) and their transience (volatile versus structural resources). In addition, the W-HR model proposes that contextual threats, such as hindering work demands, may cause conflict between work and family domains. According to this model, demands in the work domain include work overload, task ambiguity, and future work uncertainty (Cavanaugh, Boswell, Roehling, \& Boudreau, 2000; Peeters, Montgomery, Bakker, \& Schaufeli, 2005).

\section{Hypothesis development}

\section{Direct associations: Flexibility i-deals, family performance and work performance}

We expect flexibility i-deals to be positively associated with employees' work performance. A basic tenet of COR theory is that, in order to retain and obtain more resources, people are likely to invest in relevant domains (Hobfoll, 1989). Applying this perspective to the context of our study, we expect that employees will be inclined to protect their resources, such as flexibility i-deals. In order to do so, they will invest more in the work domain, so that managers will be inclined to maintain (or renew) these deals for them in the future (e.g., Halbesleben, Neveu, Paustian-Underdahl, \& Westman, 
2014). The W-HR model also supports this argument, proposing that positive resources provide enrichment within domains (e.g., Greenhaus \& Powell, 2006; Ten Brummelhuis \& Bakker, 2012).

Hypothesis 1: Flexibility i-deals are positively associated with employees' work performance.

One mechanism that may account for our proposed direct association is employees' performance in the family domain. Family performance refers to someone's engagement in a combination of family-related activities that include taking care of spouses and children (relational aspect), physical duties like fixing or repairing the home (task aspect), and making family-related decisions (cognitive aspect; Chen, Shaffer, Westman, Chen, Lazarova, \& Reiche, 2014).

In line with the inter-role enrichment perspective (Greenhaus \& Powell, 2006), which is a core element of the W-HR model, we argue that flexibility i-deals are likely to influence employees' performance in their family domain through two pathways. The first is instrumental: flexibility i-deals provide employees with discretion over where and how to work, and self-growth-oriented resources gained from one role directly improve their functioning in another role. The second pathway is affective. By definition, flexibility i-deals are individualized to employees' unique work needs and are differentiated from what others already have; hence, recipients of flexibility i-deals are likely to feel valued and happy, which positively affects their functioning in the family domain (Bakker \& Demerouti, 2012). This is supported, for example, by a study by Siu and colleagues (2015) showing enrichment between work and family domains, which demonstrates that work resources (e.g., supervisor support) relate positively to work-to-family enrichment. Similarly, Daniel and Sonnentag (2014) show that work resources (i.e., work engagement) relate to work-to-life enrichment, having an impact beyond the family, through instrumental and affective pathways, as suggested by the inter-role enrichment perspective. Our second hypothesis is:

Hypothesis 2: Flexibility i-deals are positively associated with family performance.

In addition, we argue that family performance is likely to be positively associated with work performance. In line with the inter-role enrichment perspective inherent in COR theory and the W-HR model, family performance is expected to play a motivational role by providing instrumental resources 
that help employees to achieve their work goals and perform better at work (Grzywacz \& Marks, 2000). In addition, enhanced emotional and cognitive engagement with family produces more positive affect, which is an important resource for work performance (Siu et al., 2015). For example, enjoying a relaxing day with family members, which may be a valued resource, may generate other resources such as positive emotions and gratefulness (Ten Brummelhuis et al., 2014). The latter may in turn be reinvested and enhance work performance, which in turn will help ensure that further resources are generated in the future. This is important because, according to COR theory (Hobfoll, 1989) and the W-HR model (Ten Brummelhuis \& Bakker, 2012), in order to gain and develop more resources, people utilize and re-invest the resources they possess or call on resources present in their immediate environment. Based on this principle, employees equipped with family resources are likely to devote greater attention, time and energy to work, which may lead to improved work performance (Greenhouse \& Powell, 2006; Ruderman, Ohlott, Panzer, \& King, 2002). Better family performance is likely to create enrichment, thus positively relating to work performance (Bakker \& Demerouti, 2013). Our third hypothesis is:

Hypothesis 3: Family performance is positively associated with work performance.

\section{Indirect association between flexibility i-deals and work performance}

We further argue that flexibility i-deals are positively associated with work performance through family performance. We build on the gain spiral principle of the COR theory (Hobfoll, 2002) and the W-HR model (Ten Brummelhuis \& Bakker, 2012). This principle emphasizes that people with more resources are also more capable of resource gain. Initial resource gain leads to future gain, thus creates "gain spirals". As such, acquiring resources increases the resource pool, which then makes it easier to acquire and maintain new resources. Drawing on the COR theory, the W-HR model underlines that the gain spiral can occur between work and home domains. In the context of this research, the recipients of flexibility i-deals are likely to enjoy the location and schedule discretion benefits of flexibility i-deals and achieve a better work-family balance. As a result, they are likely to accrue other resources at home such as positive emotions, gratefulness and meaning associated with 
enhanced family performance. Having acquired these resources related with better family

performance, these employees are likely to devote their time and energy into work domain in order to acquire more resources and maintain this gain spiral between domains. Research on the gain spiral of resources have supported these arguments (e.g., Llorens et al., 2007; Xanthopoulou et al., 2008). A common thread of these studies is that resource gains, either in work or home, lead to the acquisition of other resources, which ultimately creates a gain cycle. Drawing on the principle of gain spirals and recent research, we thus hypothesize an indirect association between flexibility i-deals and work performance through family performance:

Hypothesis 4: Flexibility $i$-deals are positively associated with work performance via family performance.

The role of organizational context: POS and perceived hindering work demands as moderators

A key premise underlying i-deals theory is that i-deals do not occur in a vacuum: their meaning and effectiveness depend on the wider context in which they are provided (Bal \& Rousseau, 2015; Rousseau et al., 2006). Based on the W-HR model and informed by i-deals theory, we investigate the effects of POS and perceived hindering work demands on our model. POS is relevant to understanding the consequences of flexibility i-deals for two main reasons. Flexibility i-deals involve providing a focal employee with discretion over when and where to work; however, it is not usually specified that they intend to enhance to family life (Rosen et al., 2013). Therefore, organizational support, measured broadly, aligns well with the content of flexibility i-deals, regardless of the reasons for which focal employees negotiate them. A second reason rendering POS a relevant resource relates to a defining feature of i-deals, that they intend to benefit others, beyond the recipient and manager granting the deal (Rousseau, 2005). One way to make i-deals beneficial to others in the workplace is to create and encourage an environment that supports sharing and helping. The W-HR model also proposes that POS may facilitate transferring the effects of flexibility i-deals to enhance family performance. 
Employees who perceive organizational support to be higher, may feel more comfortable in making full use of their flexibility i-deals because they observe that the organization as a whole is concerned for the wellbeing of its employees and values their contributions (Rhoades \& Eisenberger, 2002). Employees' perceptions of greater organizational support are crucial, since they may feel safer and be less likely to worry about the reactions of co-workers. This safety perception is likely to relate to their willingness to negotiate i-deals as they think the other party will agree to arrangements that advance their careers and drive their work performance (Anand, Vidyarthi, Liden, \& Rousseau, 2010). This supportiveness is likely to relate to enhanced family performance (Chen et al., 2014). For example, discretion over when and how to complete work, when coupled with supportiveness from the organization, allows employees to manage their domestic activities more effectively. This effectiveness forms a basis for family performance, such as taking care of dependent children (Gajendran \& Harrison, 2007).

In a similar vein, discretion over the time and place of work in a supportive organizational setting may reduce employee strain associated with work deadlines and pressure. Being able to work when it most suits other needs may lead to feelings of fulfilment or positive moods that are likely to enhance the cognitive element of family performance (Byron, 2005; Rothbard, 2001). Moreover, employees with flexibility i-deals are likely to plan and manage family responsibilities more proactively (Kossek, Lautsch, \& Eaton, 2006), paying greater attention to dealing with family tasks that may require not only physical presence (e.g., attending an ill child or fixing furniture at home) but also cognitive involvement (e.g., planning for holidays). Our fifth hypothesis is:

Hypothesis 5: Perceived organizational support moderates the positive association between flexibility i-deals and family performance such that this positive association is stronger (versus weaker) for employees who perceive organizational support to be high (versus low).

We expect contextual demands, namely high perceived hindering demands to create conflict between subordinates' family and work performance and be negatively associated with subordinates' work performance. According to the challenge and hindrance stressor framework (LePine et al., 2005), 
hindering work demands include role conflict, role ambiguity and job insecurity, which represent loss of resources for the focal employee, thus prevents effective work performance (Cavanaugh et al., 2000; Rodell \& Judge, 2009). Recent research on i-deals emphasizes that they may not always deliver the expected outcomes for recipients (Bal \& Rousseau, 2015). Researchers have examined the role of co-workers (Lai, Rousseau, \& Chang, 2009; Liu, Lee, Hui, Kwan, \& Wu, 2013; Marescaux, De Winne, \& Sels, 2013b) and supervisors (Anand et al., 2010; Gajendran, Harrison, \& Delaney-Klinger, 2015) to understand when the effects of i-deals are not favourable for their recipients. However, to our knowledge, researchers have not yet paid attention to the potentially detrimental role of contextual factors beyond the actors involved in i-deal making.

We argue that when hindering work demands are high, the association between family and work performance weakens, creating conflict between home and work domain. We use the buffer hypothesis of the JD-R model (Bakker \& Demerouti, 2014) which also builds on COR theory, to support our argument. Specifically, the buffer hypothesis states that the costs associated with high hindering work demands are likely to be buffered with sufficient resources employees have because these resources enable efficient coping (Bakker et al., 2005). In the context of this research, we argue that employees, who perceive hindering work demands to be high, are less likely to transfer the positive impact of family performance into work performance. In devoting their time and energy to the family domain, when hindering work demands are high, the recipients of flexibility i-deals are likely to lack the necessary resources (e.g., time, energy, attention) to devote to the work domain, which creates conflict and hence leads to deteriorating work performance. This is likely because the recipients of flexibility i-deals, when working under hindering work conditions, face resource loss and are unable to transfer the resources they have gained effectively from the family to the work domain (Bakker \& Demerouti, 2014). On the contrary, when employees perceive hindering work demands to be low, they are less likely to feel depleted and will have more energy and willingness to devote to their work. In other words, low hindering work demands are less likely to create conflict between home and work domain of the focal employee (Bakker et al., 2005). 
Research has supported the buffer hypothesis in relation to perceived hindering work demands: For example, a study by Tadic et al. (2015) showed that high hindering work demands weakened the positive association between job resources and work engagement; while low hindering work demands strengthened the positive association between job resources and well-being. Other related research has offered considerable support for the buffer hypothesis, particularly for perceived hindering work demands (e.g., Xanthopoulou, Bakker, Dollard et al., 2007). Drawing from the tenets of buffer hypothesis and research indicated above, we set our last hypothesis as below:

Hypothesis 6: Perceived hindering work demands moderate the positive association between family performance and work performance such that this positive association is stronger (versus weaker) for employees who perceive hindering work demands to be low (versus high).

\section{Method}

\section{Sample and procedure}

We investigated i-deals in the under-studied context of El Salvador. Most studies of i-deals have been conducted in North American (Anand et al., 2010) and European contexts (Hornung et al., 2010; Ng \& Feldman, 2012), but studying i-deals in other contexts is important in order to determine their potential relevance under different conditions (Las Heras, Trefalt, \& Escribano, 2015). The participants in this study were full-time employees of two large companies (one in the finance industry and the other in the hospitality industry) headquartered in El Salvador. We accessed the companies in El Salvador ${ }^{1}$ through non-academic partners ${ }^{2}$ in the country.

\footnotetext{
${ }^{1}$ Company 1, ASE is a service company founded in El Salvador in the early 1960s, which was acquired by a bank headquartered in another Latin American country in the early 2000s. ASE is certified as an AAA company by Fitch y Equilibrium (an affiliate of Moody's Investor's Service). Most employees are clerical and skilled workers. When we started our project, it had 495 employees, 184 of whom were invited to participate (151 employees and 33 supervisors). Company 2, REC was founded in the mid-1970s. It operates in the hospitality industry and has a higher number of low-skilled employees than ASE. When we started our project, it had 1,663 employees, 458 of whom were invited to participate (398 employees and 60 supervisors).

2 The non-academic partners in El Salvador are part of a Foundation whose mission is to help organizations in the country become better employers. The researchers offered survey tools and the Foundation secured access to companies. The Foundation representatives met with various organizations that might be interested in the project, with the target of recruiting at least two for the project. In El Salvador, informal workers represent 69.1 percent of total employment (Avirgan, Gammage, \& Bivens, 2005), yet a key requirement was that all
} 
The average age of subordinates was 37 years $(\mathrm{SD}=9.8$ years), and 38 percent were male.

Most had undergraduate degrees (57 percent), while 24 per cent had postgraduate degrees, 12 percent had other types of degree and six per cent had high school qualifications. The average age of supervisors was 39 years ( $\mathrm{SD}=8.1$ years), and 52 percent were male. Most supervisors had undergraduate degrees (58 percent), 40 percent had postgraduate degrees, and two percent had other types of degree. Before the study began, the company managers and employees were briefed about the purpose, procedure and confidentiality of the study.

We used online surveys. We back-translated the survey items to increase face validity (Brislin, 1986; Prieto, 1992), and granted all participants strict confidentiality, such that only the researchers had access to their responses. We collected data at separate times from subordinates and their supervisors who evaluated their work performance. We used e-mails as IDs to match the data from the subordinates and their direct supervisors. We invited 423 employees to participate in the study as subordinates, and obtained 201 fully usable responses (48 percent). We invited 143 employees to participate as supervisors, and obtained 76 responses (53 percent). Due to missing data, we finally matched 186 responses from subordinates with 59 supervisors.

\section{Measures}

Unless otherwise stated, all items were measured on a 7-point Likert scale (from 1 = strongly disagree to $7=$ strongly agree).

\section{Flexibility i-deals}

We used a scale developed by Rosen et al. (2013) to measure flexibility i-deals. The five items of this scale measured the degree to which focal employees received flexibility in their schedule ( 3 items) and location (2 items) that were different from those of their co-workers. An example item is: "At my

employees of participating companies should be formally employed. Companies participating in the project benefited from the research by receiving an in-depth company-specific executive report. The Foundation also offered to organize a public ceremony for participating companies, including El Salvador government representatives and representatives of the International Labor Organization in Central America, to recognize them as an innovative group of organizations doing research on work-family issues. 
request, my supervisor has accommodated my off-the-job demands when assigning my work hours" ( $\alpha$ $=.76)$.

\section{Family performance}

We used a scale developed by Chen et al. (2014) to evaluate subordinates' family performance. Items on the scale measured the extent to which focal employees engaged in task- (2 items), cognitive- (1 items) and relationship-oriented tasks ( 2 items) at home. One example is: "I complete household responsibilities" (relationship-oriented task; overall $\alpha=.96$ ).

\section{Work performance}

Supervisors evaluated the performance of each subordinate using four items from a scale by Williams and Anderson (1991). We selected these four items to measure the in-role work performance of focal employees. In particular, these items evaluated the extent to which subordinates met the expectations of their supervisors as well as the job (ranging from $1=$ below average to $7=$ above average). One example is: "He/she meets the formal performance requirements of the job" $(\alpha=.89)$.

\section{Perceived Organizational Support}

We used four items from a shortened version of the scale developed by Eisenberger et al. (1986) to measure POS. We chose four items that were positively worded and had the highest factor loadings. The same items had been used in previous studies, providing evidence of reliability and validity (Las Heras, Bosch, \& Raes, 2015; Snape \& Redman, 2010). An example item is: "The organization is sincerely concerned about my well-being" $(\alpha=.92)$.

\section{Perceived hindering work demands}

We used three items to measure how frequently employees experienced hindering work demands (Cavanaugh et al., 2000). We selected these items on the basis of an exploratory study in 2014 conducted prior to this study, using a similar group of participants in Mexico, funded by the WorkFamily Centre at IESE Business School, directed by the first author of this research. In the previous study, we included and measured all items from the original challenge-hindrance framework 
(Cavanaugh et al., 2000), with six items for challenge stressors and five items for hindrance stressors).

Using this sample $(\mathrm{N}=483)$, we conducted exploratory factor analysis $(\mathrm{EFA})$ with varimax rotation to select and include the highest loading items that exceeded the suggested cut-off value (0.40). This resulted in the selection of three of the eleven items. We did this because of the resource constraints of this project, particularly concerning the time allocated by managers and organizations in El Salvador. An example item is: "The amount of red tape I need to go through to get my job done" (ranging from $1=$ never to $7=$ always; $\alpha=.87)$.

\section{Control variables}

We controlled for Availability of FWPs to show the incremental explanatory power of flexibility i-deals above and beyond FWPs available to employees (Leslie et al., 2012) in our selected companies. We used seven items to measure the extent to which general flexible work practices were available in employees' organizations. An example item was: "In our organization, employees have access to compressed week hours" (seven items, ranging from $1=$ never to $7=$ always; $\alpha=.92)^{3}$.

We included the age, gender, and number of children of subordinates and their supervisors, the organization (dummy coded as 1 and 2), and the length of time of the dyadic relationship between subordinate and supervisor (measured as a continuous variable in years). We measured age and the number of children as continuous variables. We coded gender as follows: $1=$ male and $2=$ female.

\section{Analytical strategy}

Except for work performance, the variables in our model were self-rated, raising the potential for common-method bias (CMB). To address these concerns, we followed the recommendations of

\footnotetext{
${ }^{3}$ We selected the seven items based on an extensive literature review (Allen et al., 2013) and two empirical studies that have used FWPs (Leslie et al., 2012; Bal et al., 2015). In the former, the authors identified the following categories of flexibility: flexible schedules $(68 \%)$, occasional telecommuting (48\%), routine telecommuting (8\%), part-time work $(4 \%)$, compressed work weeks $(3 \%)$, and job shares $(<1 \%)$. In the latter, building on Hill et al. (2008), the authors measured the availability of FWPs, focusing on employees' work times and schedules. A meta-analysis by Allen et al. (2013) also reveals that flexibility in timing and location of work are the most prevalent types of FWP used by organizations. Drawing on these studies, we used seven items pertaining to flexibility in the number of hours worked, flexible work schedules, flexible space and options for occasional time off. In terms of validity, our items loaded significantly onto one latent factor.
} 
Podsakoff, Mackenzie, Lee, and Podsakoff (2003) and incorporated procedural remedies into our study design, including randomizing the order of scale items, randomizing items within question blocks, separating predictors and criterion variables, using different response scales for different variables, and assuring participants that researchers would treat their responses confidentially.

In line with previous suggestions (Podsakoff, MacKenzie, \& Podsakoff, 2012; Siemsen, Roth, \& Oliveira, 2010), we also conducted marker-variable analysis (Lindell \& Whitney, 2001), by subtracting the lowest positive correlation between self-reported variables from each correlation value. Each of these values was then divided by one minus the lowest positive correlation between selfreported variables, and the resulting correlation values reflected CMB-adjusted correlations. Large differences between unadjusted and CMB-adjusted correlations suggest that CMB is a problem. In our findings, the absolute differences were minimal, ranging between 0.002 and 0.001 . Correlations between the study variables reported by subordinates and the results of CFA also supported the convergent validity of our constructs. These results suggested that CMB was not a concern.

Supervisors evaluated the work performance of their subordinates (3.12 subordinates on average). To control for the nested structure of our data, we applied multi-level regression analyses using MLwiN software. To determine whether multi-level analysis was appropriate, we followed two steps. First, for our dependent variable, we evaluated the deviance statistics by building two separate models for our dependent variable using random intercept modelling (Klein et al., 2000). The model at Level 1 did not involve nesting of employees in their supervisors. We then compared this with a model at Level 2, which involved nesting of employees within their supervisors. The deviance statistics demonstrated that a model at Level 2 fitted the data significantly better than models at Level $1(\Delta-2 * \log =73.022, \mathrm{p}<.001)$.

Second, we calculated the ICC (1) for work performance to account for the proportion of the total variance attributable to differences between supervisors (Level 2): The ICC (1) for work performance was 78 percent, meaning that 78 percent of the overall variance in work performance was attributable to differences between supervisor evaluations. Our results therefore supported the use of 
multi-level regression analysis. To adequately control for both within-group and between-group variances, we used grand-mean centered estimates for all Level 1 predictors, and unit-level mean centered estimates for all Level 2 predictors (Raudenbush \& Bryk, 2002).

We first tested our hypotheses with the control variables. The direction and strength of the relationships did not change after controlling for these variables; hence, for simplicity, we excluded them from further analysis (Becker et al., 2015). In order to establish the uniqueness of our study variables, we conducted multilevel CFA (MCFA) using Mplus Version 7 (Muthén \& Muthén, 1998; 2012). To test our mediation hypothesis, consistent with recent research on multi-level mediation analysis (e.g., MacKinnon \& Fairchild, 2009; Preacher, 2015), we used the Monte Carlo method for assessing mediation (MCMAM) ${ }^{4}$. We used an online tool developed by Selig and Preacher (2008) to calculate confidence intervals. When confidence intervals do not contain zero, the indirect association is significant. We tested our moderation hypotheses, following Preacher et al.'s (2006) recommendations. To interpret the results, we plotted simple slopes at one standard deviation below and above the mean of the moderator (Aiken \& West, 1991).

\section{Results}

Table 1 displays the means, standard deviations, correlations and internal reliability values of our study variables.

Insert Table 1 here

${ }^{4}$ This approach relies on the parameter estimates and their associated asymptotic variances and co-variances. In particular, this method draws randomly from the joint distributions of the parameter estimates, calculates the product value of the two parameter estimates and repeats this a very large number of times. In the end, a confidence interval is estimated to test indirect associations (Bauer, Preacher \& Gil, 2006). 
The correlation values were of moderate size. Some correlation patterns were not in the expected direction: flexibility i-deals did not correlate with supervisor-rated work performance $(\mathrm{r}=$ $.11, \mathrm{~ns})$ or with hindering work demands $(\mathrm{r}=-.07, \mathrm{~ns})$.

Findings from MCFA revealed acceptable fit of our conceptual model: At Level 1 we included flexibility i-deals, POS, perceived hindering work demands, family performance, and FWPs. At Level 2, we included supervisor-rated work performance. This model exhibited acceptable fit with the data $(\chi 2(244)=554.44, \mathrm{p}<.001, \mathrm{CFI}=.91, \mathrm{TLI}=.90, \mathrm{SRMR}$ within $=.07$, SRMR between $=.02$, RMSEA $=.08)$.

We also assessed the model fit for three plausible alternative models based on intercorrelations of the study variables. Thus, in the first alternative model we combined flexibility i-deals and FWPs (Alternative Model 1: $\chi 2(248)=751.37, \mathrm{p}<.001, \mathrm{CFI}=.86, \mathrm{TLI}=.84$, SRMRwithin $=$ .10, SRMRbetween $=.02$, RMSEA $=.11$ ), in the second model we combined POS and family performance items (Alternative Model 2: $\chi 2(248)=1138.36, \mathrm{p}<.001, \mathrm{CFI}=.75, \mathrm{TLI}=.71$, SRMRwithin $=.14$, SRMRbetween $=.02$, RMSEA $=.14)$ and in a final model we combined POS and perceived hindering work demands items (Alternative Model 3: $\chi 2(248)=772.66, \mathrm{p}<.001, \mathrm{CFI}=.85$, $\mathrm{TLI}=.83$, SRMRwithin $=.10$, SRMRbetween $=.02$, RMSEA $=.11)$. Overall, the model fit for all alternative models was found to be inferior, so the original study model was concluded to exhibit the best fit with the data.

Hypothesis 1 proposed that flexibility i-deals would be positively associated with work performance. The findings did not support this hypothesis $(\gamma=.05, p=1.67$, n.s.; see Table 2, Model 3). Hypothesis 2 proposed that flexibility i-deals would be positively associated with family performance. The results supported this hypothesis $(\gamma=.15, \mathrm{p}<.05$; see Table 2, Model 2). Hypothesis 3 suggested that family performance would be positively associated with work performance. When we controlled for flexibility i-deals in addition to the availability of FWPs, our results supported this hypothesis $(\gamma=.09, \mathrm{p}<.01$; see Table 2 , Model 4). Hypothesis 4 postulated that flexibility i-deals would positively relate to work performance via family performance: The confidence intervals did not 
include a value of zero $(\gamma=.11(.05) ; 95 \% \mathrm{CI}=[0.002 / 0.029])$, supporting an indirect association. See Table 2 for detailed results.

Insert Table 2 here

Hypothesis 5 postulated that a higher POS would strengthen the positive association between flexibility i-deals and family performance. When we controlled for the availability of FWPs and perceived hindering work demands, our interaction term between POS and flexibility i-deals was positive and significant, providing support for Hypothesis $5(\gamma=.09, \mathrm{p}<.01$; see Table 3 , Model 3). As shown in Figure 2, the positive association between flexibility i-deals and family performance strengthened for employees who perceive organizational support to be higher $(\mathrm{z}=2.702 ; \mathrm{p}<.01)$. The association between flexibility i-deals and family performance did not change for employees who perceive organizational support to be lower $(\mathrm{z}=-0.412 ; \mathrm{p}=.68)$. Overall, Hypothesis 5 was supported (see Table 3).

Insert Table 3 here

Hypothesis 6 proposed that higher (lower) perceived hindering work demands would weaken (strengthen) the positive association between family and work performance. When we controlled for the availability of FWPs, flexibility i-deals and POS, the interaction term between family performance and perceived hindering work demands was negative and significant $(\gamma=-.06, \mathrm{p}<.01$; see Table 4 , Model 3), providing support for the hypothesis. For employees who perceived hindering work demands to be higher, the positive association between family and work performance did not change $(\mathrm{z}=1.05 ; \mathrm{p}=.295)$. The positive association between family and work performance strengthened for 
employees who perceived hindering work demands to be lower $(\mathrm{z}=3.895 ; \mathrm{p}<.01)$. Hypothesis 6 was supported (see Table 4).

Insert Table 4 here

\section{Discussion}

\section{Contributions to research on $i$-deals}

The primary contribution of this study is its focus on family performance as the mechanism through which flexibility i-deals relate to work performance $(\mathrm{H} 4)$. Our results show that flexibility ideals are not directly associated with work performance $(\mathrm{H} 1)$ but relate to work performance only via family performance (H4). This finding contradicts an assumption of i-deals theory that, on receipt of such deals, employees will perform better at work. This is because, according to the norm of reciprocity (Gouldner, 1960), provision of i-deals creates a sense of indebtedness in the focal employee toward the employer, leading to favorable behaviors of the recipient. However, a recent review study (Liao et al., 2016) and empirical papers (Bal \& Dorenbosch, 2015; Bal et al., 2015) show that reciprocity is not the only mechanism through which to understand the effects of i-deals on work performance.

We take a first step in exploring the notion that this mechanism is likely to differ for each type of i-deals because the content of different types of i-deals is different and they are independent of each other (Rousseau \& Bal, 2015). This adds to recent debates concerning how different types of i-deals are likely to influence different employee outcomes. For example, in their scale development study across four studies, Rosen et al. (2013) reveal that different types of i deals relate to different outcomes. Hornung, Rousseau, and Glaser (2008) show that flexibility i-deals reduce work-family conflict, while task i deals relate to affective commitment, increased performance expectations and paid overtime. Finally, Bal et al. (2012) demonstrate that flexibility i-deals are positively associated 
with motivation to continue working after retirement, while developmental i-deals are not.

Accordingly, in exploring family performance as a mechanism affecting the relationship between flexibility i-deals and work performance, we respond to calls for research to focus exclusively on a relevant type of i-deals (Bal et al., 2012; Hornung et al., 2009). Our results underscore that not only task and development i-deals (Hornung et al., 2009), but also flexibility i-deals may relate to higher performance, especially in the context of better work-life balance and performance in both domains as a result of i-deals.

Our second contribution relates to our focus on the influence of organizational context on the relationships of flexibility i-deals with work performance. Our findings show that subordinates' perceived organizational supportiveness is important in translating the effectiveness of flexibility ideals to the family domain. As shown in Figure 2, the association between flexibility i-deals and family performance is stronger for employees who perceive the supportiveness of their organization to be higher. Flexibility i-deals provide more observable and distinguishable resources than developmental i-deals, and thus co-workers may easily notice when focal employees have access to flexibility i-deals (Bal et al., 2012). From this perspective, it becomes clear that high perceived POS may mitigate co-workers' potentially negative reactions because, under similar conditions, co-workers may want similar i-deals to suit their own unique work needs and preferences (Anand et al., 2010). Similar lines of research have shown that employees who perceived that POS is high are more likely to feel supported by co-workers than those that feel that POS is low (Eisenberger et al., 2002; Eisenberger, Shoss, Karagonlar, Gonzalez-Morales, Wickham, \& Buffardi , 2014).

Interestingly, in previous research, Bal et al. (2012) found no support for a moderating role of perceived supportive unit climate between flexibility i-deals and motivation to continue working after retirement. One reason may relate to the age of the participants. Our sample consisted of relatively young employees $($ mean $=37.2)$ compared with Bal et al.'s $(2012)$ sample $($ mean $=42.04)$. Thus, the differences between the needs and preferences of younger and relatively older employees may explain how and when flexibility i-deals related to focal employees' home performance in our study. This is 
the first study that has explored the role of employees' perceived supportiveness of organization to understand how the recipients of flexibility i-deals use these deals to enhance their home performance.

Insert Figure 2 here

Considering the association between family and work performance, as depicted in Figure 3, our results demonstrate that for employees who perceive hindering work demands to be lower, the association between family and work performance strengthens (H6), indicating lower extent of conflict between home and work domains. Employees who receive flexibility i-deals are likely to devote more time and energy to their families and enact their family roles effectively. Indeed, effective family performance requires coordination and implementation of cognitive, affective and task duties (Chen et al., 2014) similar to the requirements of work performance (Gilboa, Shirom, Fried, \& Cooper, 2008). Therefore, when employees perceive that hindering work demands are low, they are more likely to transfer skills and opportunities gained in the family role to improve work performance (Greenhaus \& Powell, 2006). However, for employees who perceive hindering work demands to be high, the association between subordinates' home and work performance did not change. Therefore, beyond understanding whether i-deals relate to work outcomes, future studies should consider the nature of work demands, which explain when family performance associated with the use of flexibility i-deals affects work performance.

Overall, we advance i-deals research by 1 ) focusing on a particular type of i-deals rather than combining different types of i-deals together; 2) testing an overall model exploring how and when the effects of flexibility i-deals are likely to be associate with performance both in non-work and work domains; and 3) introducing the W-HR model and COR theory in the i-deals literature as novel perspectives from which to explore our model. 


\section{Contributions to individualized HRM}

We contribute to debates on the contingency approach of HRM (Kaufman \& Miller, 2011; Marescaux, De Winne, \& Sels, 2013a). These debates mainly concern the question of whether more HR practices are always associated with better employee work performance, or whether employees perform better when they access individualized HR practices. We expand these perspectives by showing that flexibility i-deals enhance work performance only for employees who perceive organizational context to be supportive and who perceive hindering work demands to be low, emphasizing the importance of a contingency approach in addition to offering individualized practices. From this perspective, we expand recent research on individualized HRM that adopts a contingency vantage point. For example, Bal and Dorenbosch (2015) show that the effect of using individualized HR practices on performance and turnover depends on employees' age. Similarly, Clinton and Guest (2013) reveal that the effects of differentiated HR practices vary across different job groups. This is the first study to go beyond individual- and team-level contingencies to understand when differentiated and individualized HR practices may be effective and beneficial.

Moreover, consistent with research on HRM (Arthur \& Boyles, 2007), it is important to distinguish between the availability of FWPs and the actual use of such practices by a select group of employees (Allen et al., 2013). In the former case, employees can access FWPs when necessary, whereas the latter makes individualized arrangements for specific employees, indicating their effectiveness for work performance (Bal et al., 2015; Rousseau, 2005). Our results support that providing flexibility i-deals to employees is positively associated with employees' work performance, after controlling for the availability of FWPs. This contributes to research on individualized HRM practices, which has only recently begun to explore the added organizational value of i-deals, above and beyond policy-based and standardized HRM implementations (e.g., Bal et al., 2015). 
We also add to the work-home enrichment literature, which underpins that work and home domains are not necessarily competitive and may enrich each other (Ten Brummelhuis \& Bakker, 2012). Our findings expand the work-family enrichment model (Greenhaus \& Powell, 2006) by integrating perceived hindering work demands as a contextual condition that influences this enrichment process, hence going beyond previous studies which have tended to focus solely on positive reinforcement (Siu et al., 2015). We also show that an individualized approach toward workers may enhance this enrichment process by enabling employees to find their own unique ways of coping with both family and work demands. As diversity increases in the workplace (Bal \& Rousseau, 2015), both employers and employees need to take an individual approach to managing work and home. Our findings show that this may indeed have beneficial effects, especially under conditions of high support and low hindering demands at work.

\section{Practical implications}

Our study provides important practical implications for managers. Our results show that they could benefit from using idiosyncratic deals, such as individualized work arrangements focused on early leave and flexitime, to address employees' unique needs through senior management involvement and commitment and the establishment of related policies, practices and procedures. Flexibility i-deals may constitute an important component of HR policies; however, contextual conditions must be considered when designing and implementing them. Previous research (Behson, 2005) found that perceived organizational support influences the transmission of the positive effects of flexibility i-deals into the family domain, while high hindering work demands prevent enrichment processes between the family and work domains, leading to a deterioration in work performance.

Companies should nurture supportive environments, for example by supporting employees when they need to leave work for non-work-related reasons (Thompson, Beauvais, \& Lyness, 1999). By providing support, employers might also avoid negative attributions from other employees, keeping employees motivated and committed (Cook, 2009). Regarding the detrimental effect of hindering work demands (e.g., draining work schedules and uncertainty of tasks or roles), senior 
management should invest in facilitating and stimulating employees to focus on both personal and jobrelated resources, and their challenging job demands (Van Wingerden, Bakker, \& Derks, 2015). In order to maximize the supportiveness of organizations and minimize hindering work demands to facilitate the implementation of flexibility i-deals, we therefore suggest that senior management should 1) invest in and carry out periodic interventions aimed at evaluating employees' resources and demands; 2) help employees fine-tune their job demands and resources, for example, by giving them more autonomy to combat hindering work demands; and 3) at the individual level, provide employees with individualized support, mentoring and coaching based on the outcomes of periodic surveys to help them optimize support and reduce hindering work demands in using flexibility i-deals. By coaching and showing understanding of employees' dual roles, supervisors might provide employees with personal resources, such as resilience and self-esteem, to combat hindering work demands (e.g., Li \& Bagger, 2011).

\section{Limitations and suggestions for further research}

As any research, this study has certain limitations. The first limitation relates to the crosssectional design of the study, which prevented testing of the causality underlying our hypotheses. We built on the W-HR model and COR theory in forming the directions of associations. Moreover, using the same analytical procedures as for Hypothesis 4, we tested two alternative models ${ }^{5}$. From our testing we can conclude that CMB is unlikely to have affected our findings. We suggest that future research should use a longitudinal design, with a pre-determined time lag between each variable (e.g.,

\footnotetext{
${ }^{5}$ In Alternative Model 1, we tested the effects of work performance on employees' flexibility i-deals that might lead to better family performance. This alternative model was based on the argument that high performers (e.g., star employees) are more likely to obtain i-deals (Rousseau et al, 2006), enabling them to perform better at home. The results did not support the indirect association between work performance and family performance through flexibility i-deals, as the confidence interval included a value of zero $(\gamma=.05(.25), \mathrm{p}=.23 ; 95 \% \mathrm{CI}=$ $[-0.030 / 0.053])$. In a second alternative model, we tested the indirect association between flexibility $\mathrm{i}$-deals and employees' family performance through employees' work performance. This model was developed from the claim that flexibility i-deals address employees' work needs and preferences (Hornung et al., 2009), leading to enhanced work performance. In turn, work performance is expected to lead to better family performance through enrichment. This indirect association was not significant, as the confidence interval included a value of zero $(\gamma=$ $.09(.50), \mathrm{p}=.18 ; 95 \% \mathrm{CI}=[-0.019 / 0.046])$.
} 
six months to a year, which would be consistent with research on i-deals; Ng \& Feldman, 2014). This would enable researchers to explore the processual nature of the proposed model in sequence.

In relation to this limitation, for future studies, researchers might consider a within-person design to explore the effects of flexibility i-deals. For example, future research might explore the effects of flexibility i-deals on family and work performance on a weekly basis. Perceived organizational support and hindering work demands might be conceptualized as trait moderators influencing our proposed indirect associations. Such a design would appear to be a novel approach, in that recent conceptual discussions on i-deals have emphasized that employees may strike micro i-deals that might show variation across time (Bal \& Rousseau, 2015). This might be particularly interesting for flexibility i-deals that vary from week to week, such as leaving work earlier, having flexibility to work from home or changing locations.

A second limitation relates to our focus on perceived hindering work demands. Our results reveal that the association between family and work performance weakens for employees who perceive high hindering work demands. However, this association might strengthen under conditions of high challenging work demands (Bakker \& Demerouti, 2014). Future research might test the differential effects of hindering versus challenging work demands on the effects of flexibility i-deals on both non-work and work domains.

In addition, this study expands the W-HR model by incorporating enrichment and conflict hypotheses into the same framework and testing how contextual resources and demands at work act as boundary conditions for our proposed associations (Bakker \& Demerouti, 2013). Future studies might integrate resources and demands from a different domain, such as emotional support or emotional demands at home (Bhave, Kramer \& Glomb, 2010), and explore how the effects of a different type of i-deals (e.g., career i-deals) are shaped by these contextual conditions. For example, while our results reveal no direct association between flexibility i-deals and work performance, the content of task i-deals suggests that they might relate to work performance. Understanding the underlying mechanisms and contextual conditions for the effects of task i-deals remains unaddressed by research to date. 
In exploring the effects of POS, we assumed that co-workers' reactions to focal employees' ideals would be tempered in supportive organizations. We suggest future research to take account of co-workers and explore the effectiveness of focal employees' i deals from a co-worker perspective (Ng \& Lucianetti, 2016). In line with the predictions of fairness theories, employees who do not have access to i-deals may create a competitive and stressful work environment, offsetting the positive effects of a supportive organizational context. In order to understand when i-deals translate into effective implementation in the family and work domains, future research might investigate coworkers' cognitive responses (i.e., perceived fairness of i-deals) and emotional reactions (e.g., envy, anger).

In addition to contextual resources and demands at work, researchers might integrate dispositional contextual factors to understand when flexibility i-deals translate into better family and work performance. One interesting approach might be to integrate employees' work-family boundary management preferences, in terms of "integrators" and "segmenters" (Kreiner, 2006). Recent research has shown that employees who prefer role integration are better able to deal with work expectations and technology use after work than those who prefer role segmentation between the two domains (Piszczek, 2016). Future studies might adopt a boundary management perspective to disentangle the effects of flexibility i-deals on employees' non-work domains (e.g., family, personal hobbies).

Future research might also integrate and explore the cross-over effects of flexibility i deals. Their potential benefits may cross over to focal employees' spouses at home, enabling them to perform better at work. Such an approach might contribute to the conceptualization of i-deals by investigating whether and how the benefits of i deals go beyond the work domain to include recipients' spouses. This would also enable exploration of relevant social and psychological mechanisms, such as emotional, cognitive and physical partner support, which would enrich the ideals literature and the W-HR model. 


\section{References}

Aiken, L. S., \& West, S. G. (1991). Multiple regression: Testing and interpreting interactions. Newbury Park: Sage.

Allen, T. D. (2001). Family supportive work environments: The role of organizational perceptions. Journal of Vocational Behavior, 3, 414-435. 10.1006/jvbe.2000.1774

Allen, T. D., Herst, D. E. L., Bruck, C. S., \& Sutton, M. (2000). Consequences associated with work-to-family conflict: A review and agenda for future research. Journal of Occupational Health Psychology, 5, 278-308. 10.1037//1076-8998.5.2.278

Allen, T. D., Johnson, R. C., Kiburz, K. M., \& Shockley, K. M. (2013). Work-family conflict and flexible work arrangements: Deconstructing flexibility. Personnel Psychology, 66, 345-376. 10.1111/peps.12012

Allen T. D., \& Shockley K. (2009). Flexible work arrangements: Help or hype? In Crane, R., \& Hill, J. (Eds.), Handbook of families and work: Interdisciplinary perspectives (pp. 265284). Lanham, MD: University Press of America.

Anand, S., Vidyarthi, P. R., Liden, R. C., \& Rousseau, D. M. (2010). Good citizens in poorquality relationships: Idiosyncratic deals as a substitute for relationship quality. Academy of Management Journal, 53, 970-988. 10.5465/AMJ.2010.54533176

Arthur, J. B., \& Boyles, T. (2007). Validating the human resource system structure: A levelsbased framework for strategic HRM research. Human Resource Management Review, 17, 77-92. 10.1016/j.hrmr.2007.02.001

Avirgan, T., Bivens, L. J., \& Gammage, S., Eds. (2005). Good jobs, bad jobs, no jobs: Labor markets and informal work in Egypt, El Salvador, India, Russia, and South Africa. Washington, DC: Economic Policy Institute. 
Bakker, A. B. (2013). Top-down and bottom-up interventions to increase work engagement. In Hartung, P., Savickas, M., \& Walsh, B. (Eds.), APA handbook of career intervention. Washington, DC: American Psychological Association.

Bakker, A. B., Demerouti, E., \& Euwema, M. C. (2005). Job resources buffer the impact of job demands on burnout. Journal of Occupational Health Psychology, 10(2), 170-180. doi:10.1037/1076-8998.10.2.170

Bakker, A. B., \& Demerouti, E. (2007). The job demands-resources model: State of the art. Journal of Managerial Psychology, 22, 309-328. 10.1108/02683940710733115

Bakker, A. B., \& Demerouti, E. (2013). The spillover-crossover model. In Grzywacs, J., \& Demerouti, E. (Eds.), New frontiers in work and family research (pp. 54-70). Hove: Psychology Press.

Bakker, A. B., \& Demerouti, E. (2014). Job demands-resources theory. In Cooper, C., \& Chen, P. (Eds.), Wellbeing: A complete reference guide (pp. 37-64). Chichester, UK: WileyBlackwell.

Bal, P. M., \& Dorenbosch, L. (2015). Age-related differences in the relations between individualised HRM and organizational performance: A large-scale employer survey. Human Resource Management Journal, 25, 41-61. 10.1111/1748-8583.12058

Bal, P. M., De Jong, S. B., Jansen, P. G. W., \& Bakker, A. B. (2012). Motivating employees to work beyond retirement: A multi-level study of the role of I-deals and unit climate. Journal of Management Studies, 49, 306-331. 10.1111/j.1467-6486.2011.01026.x

Bal, P. M., Kleef, M. V., \& Jansen, P. G. (2015). The impact of career customization on work outcomes: Boundary conditions of manager support and employee age. Journal of Organizational Behavior, 36, 421-440. 10.1002/job.1998 
Bal, P. M., \& Rousseau, D. M. (2015). Idiosyncratic deals between employees and organizations: Conceptual issues, applications and the role of co-workers. Oxford: Taylor \& Francis Group.

Behson, S. J. (2005). The relative contribution of formal and informal organizational workfamily support. Journal of Vocational Behavior, 66, 487-500. 10.1016/j.jvb.2004.02.004

Becker, T. E., Atinc, G., Breaugh, J. A., Carlson, K. D., Edwards, J. R., \& Spector, P. E. (2015). Statistical control in correlational studies: 10 essential recommendations for organizational researchers. Journal of Organizational Behavior, 37, 157-167. doi: 10.1002/job.2053

Benko, C., \& Weisberg, A. (2007). Mass career customization: Aligning the workplace with today's nontraditional workforce. Boston, MA: Harvard Business School Press.

Bhave, D. P., Kramer, A., \& Glomb, T. M. (2010). Work-family conflict in work groups: Social information processing, support, and demographic dissimilarity. Journal of Applied Psychology, 95, 145-158. 10.1037/a0017885

Brislin, R. W. (1986). The wording of translation of research instruments. In: Lonner, W. J., \& Berry, J. W. (Eds.), Field methods in cross-cultural research (pp. 137-164). Beverly Hills, CA: Sage.

Byron, K. (2005). A meta-analytic review of work-family conflict and its antecedents. Journal of Vocational Behavior, 2, 169-198. 10.1016/j.jvb.2004.08.009

Cavanaugh, M. A., Boswell, W. R., Roehling, M. V., \& Boudreau, J. W. (2000). An empirical examination of self-reported work stress among U.S. managers. The Journal of Applied Psychology, 85, 65-74. 10.1037//0021-9010.85.1.65

Chen, Y.-P., Shaffer, M., Westman, M., Chen, S., Lazarova, M., \& Reiche, S. (2014). Family role performance: Scale development and validation. Applied Psychology: An International Review, 63, 190-218. 10.1111/apps.12005 
Clinton, M., \& Guest, D. E. (2013). Testing universalistic and contingency HRM assumptions across job levels. Personnel Review, 42, 529-551. 10.1108/PR-07-2011-0109

Conway, N., \& Coyle-Shapiro, J. (2015). Not so I-deal: A critical review of idiosyncratic- deals theory and research. In Bal, P. M., \& Rousseau, D. M. (Eds.), Idiosyncratic deals between employees and organizations: Conceptual issues, applications, and the role of coworkers (pp. 201-45). London: Psychology Press.

Cook, A. (2009). Connecting work-family policies to supportive work environments. Group \& Organization Management, 34, 206-240. 10.1177/1059601108330091

Daniel, S., \& Sonnentag, S. (2014). Work to non-work enrichment: The mediating roles of positive affect and positive work reflection. Work \& Stress, 28, 49-66. $10.1080 / 02678373.2013 .872706$

De Menezes, L. M., \& Kelliher, C. (2011). Flexible working and performance: A systematic review of the evidence for a business case. International Journal of Management Reviews, 13, 452-474. 10.1111/j.1468-2370.2011.00301.x

Demerouti, E., Bakker, A. B., \& Voydanoff, P. (2010). Does home life interfere with or facilitate performance? European Journal of Work and Organizational Psychology, 19, 128-149. 10.1080/13594320902930939

Eisenberger, R., Huntington, R., Hutchison, S., \& Sowa, D. (1986). Perceived organizational support. Journal of Applied Psychology, 71, 500-507. 10.1037/0021-9010.71.3.500

Eisenberger, R., Shoss, M. K., Karagonlar, G., Gonzalez-Morales, M. G., Wickham, R. E., \& Buffardi, L. C. (2014). The supervisor POS-LMX-subordinate POS chain: Moderation by reciprocation wariness and supervisor's organizational embodiment. Journal of Organizational Behavior, 35, 635-656. 10.1002/job.1877

Eisenberger, R., Stinglhamber, F., Vandenberghe, C, Sucharski, I., \& Rhoades, L. (2002). Perceived supervisor support: Contributions to perceived organizational support and 
employee retention. Journal of Applied Psychology, 87, 365-373. 10.1037/00219010.87 .3 .565

Ellis, P. D. (2010). The essential guide to effect sizes: Statistical power, meta-analysis, and the interpretation of research results. Cambridge: Cambridge University Press.

Gajendran, R. S., \& Harrison, D. A. (2007). The good, the bad, and the unknown about telecommuting: Meta-analysis of psychological mediators and individual consequences. Journal of Applied Psychology, 6, 1524-1541. 10.1037/0021-9010.92.6.1524

Gajendran, R. S., Harrison, D. A., \& Delaney-Klinger, K. (2015). Are telecommuters remotely good citizens? Unpacking telecommuting's effects on performance via i-deals and job resources. Personnel Psychology, 68, 353-393. 10.1111/peps.12082

Gilboa, S., Shirom, A., Fried, Y., \& Cooper, C. (2008). A meta-analysis of work demand stressors and job performance: Examining main and moderating effects. Personnel Psychology, 61, 227-271. 10.1111/j.1744-6570.2008.00113.x

Glassner, V. \& Keune, M. (2012). The crisis and social policy: The role of collective agreements. International Labor Review, 151, 351-375. 10.1111/j.1564913X.2012.00153.X

Gouldner, A. W. (1960). The norm of reciprocity: A preliminary statement. American Sociological Review, 25, 161-78. 10.2307/2092623

Greenberg, J., Roberge, M. E., Ho, V. T., \& Rousseau, D. (2004). Fairness as an “i-deal”: Justice in under-the-table employment arrangements. In Martochio, J. J. (Ed.), Research in personnel and human resources management, (pp. 1-34). Oxford: JAI Press.

Greenhaus, J. H., Callanan, G. A., \& Godshalk, V. M. (2010). Career management, 4th edition. Newbury Park, CA: Sage. 
Greenhaus, J. H., \& Powell, G. N. (2006). When work and family are allies: A theory of work family enrichment. Academy of Management Review, 31, 72-92. 10.5465/AMR.2006.19379625

Grzywacz, J. G., \& Marks, N. F. (2000). Family, work, work-family spillover, and problem drinking during midlife. Journal of Marriage and Family, 62, 336-348. 10.1111/j.17413737.2000.00336.x

Guest, D. E., \& Rodrigues, R. (2015). Career control. In De Vos, H., \& Van der Heijden, B. (Eds.), Handbook of research on sustainable careers: Aims, approach and outline (pp. 205-222). Cheltenham: Edward Elgar Publishing Limited.

Halbesleben, J. R. B., Neveu, J.-P., Paustian-Underdahl, S. C., \& Westman, M. (2014). Getting to the "COR": Understanding the role of resources in conservation of resources theory. Journal of Management, 40, 1334-1364. 10.1177/0149206314527130

Hammer, L. B., Kossek, E. E., Yragui, N. L., Bodner, T. E., \& Hanson, G. C. (2009). Development and validation of a multidimensional mea- sure of family supportive supervisor behaviors (FSSB). Journal of Management, 35, 837- 856. http://dx.doi.org/10.1177/0149206308328510

Hammer, L. B., Kossek, E. E., Zimmerman, K. L., \& Daniels, R. (2007). Clarifying the construct of family-supportive supervisory behaviors (FSSB): A multilevel perspective. In P. L. Perrewé \& D. C. Ganster (Eds.), Research in occupational stress and well-being (Vol. 6, pp. 171-211). Amsterdam, Netherlands: Emerald.

Hayton, J. C., Carnabuci, G. \& Eisenberger, R. (2012). With a little help from my colleagues: A social embeddedness approach to perceived organizational support. Journal of Organizational Behavior, 33, 235-249. 10.1002/job.755

Hill, E. J., Jacob, J. I., Shannon, L. L., Brennan, R. T., Blanchard, V. L., \& Martinengo, G. (2008). Exploring the relationship of workplace flexibility, gender, and life stage to family- 
to-work conflict, and stress and burnout. Community, Work \& Family, 11, 165-181. $10.1080 / 13668800802027564$

Hobfoll, S. E. (1989). Conservation of resources: A new attempt at conceptualizing stress. American Psychologist, 44, 513-524. 10.1037/0003-066X.44.3.513

Hobfoll, S. E. (2002). Social and psychological resources and adaptation. Review of General Psychology, 6, 307-324. 10.1037/1089-2680.6.4.307

Hobfoll, S. E., Vaux, A., \& Breznitz, L. G. S. (1993). Social support: Social resources and social context Handbook of stress: Theoretical and clinical aspects, 2nd ed. (pp. 685-705). New York, NY: Free Press.

Hornung, S., Rousseau, D. M., \& Glaser, J. (2008). Creating flexible work arrangements through idiosyncratic deals. Journal of Applied Psychology, 93, 655-664. 10.1037/00219010.93.3.655

Hornung, S., Rousseau, D. M., \& Glaser, J. (2009). Why supervisors make idiosyncratic deals. Journal of Managerial Psychology, 24, 738-764. 10.1108/02683940910996770

Hornung, S., Rousseau, D. M., Glaser, J., Angerer, P., \& Weigl, M. (2010). Beyond top-down and bottom-up work redesign: Customizing job content through idiosyncratic deals. Journal of Organizational Behavior, 31, 187-215. 10.1002/job.625

Hox, J. (2002). Multilevel analysis. Techniques and applications. Mahwah, NJ: Erlbaum.

Hu, L.-T., \& Bentler, P. M. (1999). Cutoff criteria for fit indices in covariance structure analysis: Conventional criteria versus new alternatives. Structural Equation Modeling, 6, 1-55. 10.1080/10705519909540118

Kaufman, B. E., \& Miller, B. I. (2011). The firm's choice of HRM practices: Economics meets strategic human resource management. Industrial and Labor Relations Review, 64, 526557. $10.1177 / 001979391106400306$ 
Kossek, E. E., Lautsch, B. A., \& Eaton, S. C. (2006). Telecommuting, control, and boundary management: Correlates of policy use and practice, job control, and work-family effectiveness. Journal of Vocational Behavior, 2, 347-367. 10.1016/j.jvb.2005.07.002

Kreiner, G. E. (2006). Consequences of work-home segmentation or integration: A personenvironment fit perspective. Journal of Organizational Behavior, 27, 485-507. $10.1002 /$ job.386

Lai, L., Rousseau, D. M., \& Chang, T. T. (2009). Idiosyncratic deals: Coworkers as interested third parties. Journal of Applied Psychology, 94, 547-556. 10.1037/a0013506

Las Heras, M., Bosch, M. J., \& Raes, A. M. (2015). Sequential mediation among family friendly culture and outcomes. Journal of Business Research, 68, 2366-2373. 10.1016/j.jbusres.2015.03.042

Las Heras, M., Trefalt, S., \& Escribano, P. I. (2015). How national context moderates the impact of family-supportive supervisory behavior on job performance and turnover intentions. Management Research: Journal of the Iberoamerican Academy of Management, 13, 5582. 10.1108/MRJIAM-06-2014-0556

Leslie, L. M., Manchester, C. F., Park, T.-Y., \& Mehng, S. A. (2012). Flexible work practices: A source of career premiums or penalties? Academy of Management Journal, 55, 14071428. $10.5465 / \mathrm{amj} .2010 .0651$

LePine, J. A., Podsakoff, N. P., \& LePine, M. A. (2005). A meta-analytic test of the challenge stressor-hindrance stressor framework: An explanation for inconsistent relationships among stressors and performance. Academy of Management Journal, 48, 764-775. doi:10.5465/amj.2005. 18803921

Li, A., \& Bagger, J. (2011). Walking in your shoes: Interactive effects of child care responsibility difference and gender similarity on supervisory family support and work- 
related outcomes. Group \& Organization Management, 36, 659-691. $10.1177 / 1059601111416234$

Liao, C., Wayne, S., \& Rousseau, D. M. (2016). Idiosyncratic deals in contemporary organizations: A qualitative and meta-analytical review. Journal of Organizational Behavior, 1, 9-29. 10.1002/job.1959

Lindell, M. K., \& Whitney, D. J. (2001). Accounting for common method variance in crosssectional research designs. Journal of Applied Psychology, 86, 114-21. 10.1037//00219010.86 .1 .114

Liu, J., Lee, C., Hui, C., Kwan, H. K., \& Wu, L. Z. (2013). Idiosyncratic deals and employee outcomes: The mediating roles of social exchange and self-enhancement and the moderating role of individualism. Journal of Applied Psychology, 98, 832-840. $10.1037 / \mathrm{a} 0032571$

Llorens, S., Schaufeli, W. B., Bakker, A. B., \& Salanova, M. (2007). Does a positive gain spiral of resources, efficacy beliefs and engagement exist? Computers in Human Behavior, 23, $825-841$.

MacKinnon, D. P., \& Fairchild, A. J. (2009). Current directions in mediation analysis. Current Directions in Psychological Science, 18, 16-20. 10.1111/j.1467-8721.2009.01598.x

Marescaux, E., De Winne, S., \& Sels, L. (2013a). HR practices and affective organizational commitment: When does HR differentiation pay off? Human Resource Management Journal, 23, 329-345. 10.1111/1748-8583.12013

Marescaux E., De Winne S., \& Sels, L. (2013b). Co-worker reactions to i-deals: A distributive justice perspective. Paper presented at the 73rd Academy of Management Annual Conference, Buena Vista, USA.

Muthén, L. K., \& Muthén, B. O. (2012). Mplus user's guide. Los Angeles, CA: Muthén \& Muthén. 
Nielson, T. R., Carlson, D. S., \& Lankau, M. J. (2001). The supportive mentor as a means of reducing work-family conflict. Journal of Vocational Behavior, 59, 364-381. 10.1006/jvbe.2001.1806

Ng., T. W. H. \& Feldman, D. C. (2012). Idiosyncratic deals and voice behavior. Journal of Management, 13, 33-45. 10.1177/0149206312457824

Ng., T. W. H. \& Lucianetti, L. (2016). Goal striving, idiosyncratic deals and job behavior. Journal of Organizational Behavior, 37, 41-60. 10.1002/job.2023

Paustian-Underdahl, S. C., \& Halbesleben, J. R. B. (2014). Examining the influence of climate, supervisor guidance, and behavioral integrity on work-family conflict: A demands and resources approach. Journal of Organizational Behavior, 35, 447-463. 10.1002/job.1883

Peeters, M. C. W., de Jonge, J., Janssen, P. P. M., \& van der Linden, S. (2004). Work-home interference, job stressors and employee health in a longitudinal perspective. International of Stress Management, 11, 305-322. 10.1111/j.1365-2648.2008.04630.x

Peeters, M., Montgomery, A. J., Bakker, A. B., \& Schaufeli, W. B. (2005). Balancing work and home: How job and home demands are related to each other. International Journal of Stress Management, 12, 43-61. 10.1037/1072-5245.12.1.43

Piszczek, M. (2016). Boundary control and controlled boundaries: Organizational expectations for technology use at the work-family interface. Journal of Organizational Behavior. 10.1002/job. 2153

Podsakoff, P. M., MacKenzie, S. B., Lee, J., \& Podsakoff, N. P. (2003). Common method bias in behavioral research: A critical review of the literature and recommended remedies. Journal of Applied Psychology, 88, 879-903. 10.1037/0021-9010.88.5.879

Podsakoff, P. M., MacKenzie, S. B., \& Podsakoff, N. P. (2012). Sources of method bias in social science research and recommendations on how to control it. Annual Review of Psychology, 65, 539-569. 10.1146/annurev-psych-120710-100452. 
Preacher, K.J., Curran, P.J., \& Bauer, D.J. (2006). Computational Tools for Probing Interactions in Multiple Linear Regression, Multilevel Modeling, and Latent Curve Analysis. Journal of Educational and Behavioral Statistics, 31, 437-448. $10.3102 / 10769986031004437$

Preacher, K. J. (2015). Advances in mediation analysis: A survey and synthesis of new developments. Annual Review of Psychology, 66, 825-852. 10.1146/annurev-psych010814-015258

Prieto, A. (1992). A method for translation of instruments to other languages. Adult Education Quarterly, 43, 1-14. 10.1177/0741713692043001001

Raudenbush, S. W., \& Bryk, A. S. (2002). Hierarchical linear models: Applications and data analysis methods, 2nd edition. Newbury Park, CA: Sage.

Rhoades, L., \& Eisenberger, R. (2002). Perceived organizational support: A review of the literature. Journal of Applied Psychology, 87, 698-714. 10.1037/0021-9010.87.4.698

Rodell, J. B., \& Judge, T. A. (2009). Can "good" stressors spark "bad" behaviors? The mediating role of emotions in links of challenge and hindrance stressors with citizenship and counterproductive behaviors. Journal of Applied Psychology, 94, 1438-1451. $10.1037 / \mathrm{a} 0016752$

Rofcanin, Y. (2016). 'HR differentiation: a double-edged sword?', unpublished PhD dissertation, University of Warwick, Coventry.

Rosen, C. C., Slater, D. J., Chang, C. H., \& Johnson, R. E. (2013). Let's make a deal: Development and validation of the ex post I-deals scale. Journal of Management, 39, 709742. $10.1177 / 0149206310394865$

Rothbard, N. (2001). Enriching or depleting? The dynamics of engagement in work and family roles. Administrative Science Quarterly, 46, 655-684. 10.2307/3094827 
Rousseau, D. M. (2005). I-deals: Idiosyncratic deals employees bargain for themselves. New York: M. E. Sharpe.

Rousseau, D. M., Ho, V. T., \& Greenberg, J. (2006). I-deals: Idiosyncratic terms in employment relationships. Academy of Management Review, 31, 977-994.

Rousseau, D. M., Hornung, S., \& Kim, T. G. (2009). Idiosyncratic deals: Testing propositions on timing, content, and the employment relationship. Journal of Vocational Behavior, 74, 338-348. 10.1016/j.jvb.2009.02.004

Rousseau, D. M., \& Kim, T. G. (2006). When workers bargain for themselves: Idiosyncratic deals and the nature of the employment relationship. Paper presented at the British Academy of Management Conference, Belfast, Ireland.

Ruderman, M. N., Ohlott, P. J., Panzer, K., \& King, S. N. (2002). Benefits of multiple roles for managerial women. Academy of Management Journal, 45, 369-386. 10.2307/3069352

Salanova, M., Schaufeli, W.B., Xanthopoulou, D., \& Bakker, A.B. (2010). The gain spiral of resources and work engagement: Sustaining a positive worklife. In A.B. Bakker \& M.P. Leiter (Eds.), Work engagement: A handbook of essential theory and research (pp. 118131). New York: Psychology Press.

Selig, J. P., \& Preacher, K. J. (2008). Monte Carlo method for assessing mediation: An interactive tool for creating confidence intervals for indirect effects [computer software]. Available from: http://quantpsy.org/.

Shore, L. M., \& Wayne, S. J. (1993). Commitment and employee behavior: Comparison of affective commitment and continuance commitment with perceived organizational support. Journal of Applied Psychology, 78, 774-780. 10.1037/0021-9010.78.5.774

Siemsen, E., Roth, A., \& Oliveira, P. (2010). Common method bias in regression models with linear, quadratic, and interaction effects. Organizational research methods, 13, 456-476. $10.1177 / 1094428109351241$ 
Snape, E., \& Redman, T. (2010). HRM practices, organizational citizenship behaviour, and performance: A multi-level analysis. Journal of Management Studies, 47, 55-95. 10.1111/j.1467-6486.2009.00911.x

Tadic, M., Bakker, A.B., \& Oerlemans, W.G.M. (2015). Challenge versus hindrance job demands and well-being: A diary study on the moderating role of job resources. Journal of Occupational and Organizational Psychology 88, 702-725.

Ten Brummelhuis, L. L., \& Bakker, A. B. (2012). A resource perspective on the work-home interface: The work-home resources model. American Psychologist, 67, 545-556. $10.1037 / \mathrm{a} 0027974$

Ten Brummelhuis, L. L., Haar, J. M., \& Roche, M. (2014). Does family life help to be a better leader? A closer look at crossover processes from leaders to followers. Personnel Psychology, 67, 917-949. 10.1111/peps.12057

Thompson, C. A., Beauvais, L. L., \& Lyness, K. S. (1999). When work-family benefits are not enough: The influence of work-family culture on benefit utilization, organizational attachment, and work-family conflict. Journal of Vocational Behavior, 54, 329-415. 10.1006/jvbe.1998.1681

Xanthopoulou, D., Bakker, A. B., Dollard, M. F., Demerouti, E., Schaufeli, W. B., Taris, T. W., \& Schreurs, P. J. G. (2007). When do job demands particularly predict burnout?: The moderating role of job resources. Journal of Managerial Psychology, 22, 766-786. doi:10.1108/02683940710837714

Xanthopoulou, D., Bakker, A. B., Heuven, E., Demerouti, E., \& Schaufeli, W. B. (2008). Working in the sky: A diary study on work engagement among flight attendants. Journal of Occupational Health Psychology, 13, 345-356. doi: 10.1037/1076-8998.13.4.345. 
Van Wingerden, J., Bakker, A. B., \& Derks, D. (2016). A test of a job demands-resources intervention. Journal of Managerial Psychology, 31, 686-701. 10.1108/JMP-03-20140086

Vidyarthi, P. R., Chaudhry, A., Anand, S., \& Liden, R. C. (2014). Flexibility i-deals: How much is ideal? Journal of Managerial Psychology, 29, 246-265. 10.1108/JMP-07-2012-0225

Williams, L. J., \& Anderson, S. E. (1991). Job satisfaction and organizational commitment as predictors of organizational citizenship and in-role behavior. Journal of Management, 17, 601-617. 10.1177/014920639101700305 
Table 1. Means, standard deviations, reliabilities and correlations

\begin{tabular}{|c|c|c|c|c|c|c|c|c|c|c|c|c|c|c|c|c|c|}
\hline & Variables & Means & S.D. & 1 & 2 & 3 & 4 & 5 & 6 & 7 & 8 & 9 & 10 & 11 & 12 & 13 & 14 \\
\hline 1 & Age of subordinates & 37.73 & 9.81 & -- & & & & & & & & & & & & & \\
\hline 2 & Gender of subordinates & 1.92 & - & 0.03 & -- & & & & & & & & & & & & \\
\hline 3 & Number of children of subordinates & 2.87 & 1.24 & 0.14 & 0.001 & -- & & & & & & & & & & & \\
\hline 4 & Age of supervisors & 39.01 & 8.13 & $0.31 * *$ & 0.006 & 0.04 & -- & & & & & & & & & & \\
\hline 5 & Gender of supervisors & 1.15 & - & 0.04 & 0.07 & 0.02 & $0.27^{* *}$ & -- & & & & & & & & & \\
\hline 6 & Number of children of supervisors & 3.11 & 1.07 & 0.11 & 0.05 & 0.07 & 0.08 & $0.26 * *$ & -- & & & & & & & & \\
\hline 7 & Organization & 1.31 & 0.49 & 0.05 & 0.04 & 0.09 & $0.12 *$ & 0.09 & 0.08 & -- & & & & & & & \\
\hline 8 & Dyadic Tenure & 3.15 & 0.58 & 0.07 & 0.06 & 0.11 & 0.09 & 0.07 & 0.07 & 0.05 & -- & & & & & & \\
\hline 9 & Availability of FWPs & 3.49 & 1.31 & 0.08 & 0.04 & 0.05 & 0.07 & 0.12 & 0.05 & $0.19 *$ & 0.08 & $(0.92)$ & & & & & \\
\hline 10 & Flexibility I-Deals & 4.59 & 1.47 & 0.05 & 0.01 & 0.02 & 0.06 & 0.12 & 0.04 & 0.05 & $0.13^{*}$ & $0.26 * *$ & $(0.76)$ & & & & \\
\hline 11 & Family Performance & 5.87 & 1.17 & 0.14 & 0.07 & 0.02 & 0.04 & 0.02 & 0.09 & 0.09 & 0.06 & 0.17 & $0.21 * *$ & $(0.96)$ & & & \\
\hline 12 & Work Performance & 6.41 & 0.78 & 0.07 & 0.03 & 0.05 & 0.12 & 0.03 & 0.11 & $0.12 *$ & 0.07 & 0.04 & 0.11 & $0.22 * *$ & $(0.89)$ & & \\
\hline 13 & POS & 5.43 & 1.25 & 0.07 & 0.04 & 0.04 & 0.06 & 0.03 & 0.08 & 0.08 & 0.06 & $0.30 * *$ & $0.39 * *$ & $0.19 *$ & 0.03 & $(0.92)$ & \\
\hline 14 & Hindering Work Demands & 5.08 & 1.33 & 0.01 & 0.07 & 0.18 & 0.08 & 0.02 & 0.03 & 0.07 & 0.04 & -0.03 & -0.07 & $-0.21 *$ & -0.06 & -0.12 & $(0.87)$ \\
\hline
\end{tabular}

Notes. Reliabilities are along the diagonal in parentheses, where applicable. 
FWPs: Flexible work practices; POS: Perceived organizational support.

$1=$ male, 2 = female. Organization was dummy-coded as 1 and 2 . Age, number of children and dyadic tenure were measured on a continuous scale. $\mathrm{n}=186$ subordinates; 59 supervisors.

$* \mathrm{p}<0.05 ; * * \mathrm{p}<0.01 ; * * \mathrm{p}<0.001$ 
Table 2. Direct associations among flexibility i-deals, family performance and work performance

\begin{tabular}{|c|c|c|c|c|c|c|c|c|c|c|c|c|}
\hline \multirow[b]{2}{*}{ Variables } & \multicolumn{6}{|c|}{ Family Performance } & \multicolumn{6}{|c|}{ Work Performance } \\
\hline & Estimate & S.E. & $\mathrm{t}$ & Estimate & S.E. & $\mathrm{t}$ & Estimate & S.E. & $\mathrm{t}$ & Estimate & S.E. & $\mathrm{t}$ \\
\hline Intercept & 5.88 & 0.08 & 73.50 & 5.88 & 0.08 & 73.50 & 6.19 & 0.12 & 51.55 & 6.20 & 0.15 & 41.33 \\
\hline Availability of FWPs & 0.13 & 0.06 & $2.17^{*}$ & 0.08 & 0.07 & 1.14 & 0.02 & 0.04 & 0.51 & 0.02 & 0.05 & 0.41 \\
\hline Family Performance & & & & & & & & & & 0.09 & 0.03 & $3.00 * *$ \\
\hline$-2 \mathrm{LL}$ & 578.79 & & & 572.08 & & & 360.54 & & & 352.77 & & \\
\hline$\Delta-2 \mathrm{LL}$ & $3.90^{* a}$ & & & $6.71 * *$ & & & $4.21^{b}$ & & & $7.77^{* *}$ & & \\
\hline Standard Error & \multicolumn{3}{|c|}{$0.01(0.02)$} & \multicolumn{3}{|l|}{$0.01(0.02)$} & \multicolumn{3}{|c|}{$0.20(0.02)$} & \multicolumn{3}{|l|}{$0.20(0.02)$} \\
\hline \multicolumn{13}{|c|}{ Level 2 Intercept Variance Standard } \\
\hline Error & \multicolumn{3}{|c|}{$1.33(0.13)$} & \multicolumn{3}{|l|}{$1.29(0.13)$} & \multicolumn{3}{|c|}{$0.73(0.15)$} & \multicolumn{3}{|l|}{$0.71(0.14)$} \\
\hline
\end{tabular}

Notes: ${ }^{\text {b }}$ Statistical comparison with an intercept-only model 1 (not shown in the table).

FWPs: Flexible work practices. 
The indirect effect is calculated using an on-line interactive tool that generates an R score: http://quantpsy.org/medmc/medmc.htm.

The first path of the indirect relationship relates to the association between flexibility i-deals and family performance $(0.15 ; 0.06)$ and the second path of the indirect relationship relates to the association between family and work performance $(0.09 ; 0.03)$ when flexibility $\mathrm{i}$-deals is present in the equations. For all values, gamma coefficients, their corresponding standard error and $t$ values are reported.

$\mathrm{n}=186$ subordinates; 59 supervisors.

${ }^{*} p<0.05 ; * * p<0.01 ; * * * p<0.001$. 
Table 3. Moderation analyses results for family performance

\begin{tabular}{|c|c|c|c|c|c|c|c|c|c|}
\hline \multirow[b]{3}{*}{ Variables } & \multicolumn{9}{|c|}{ Family Performance } \\
\hline & \multicolumn{3}{|c|}{ Model 1} & \multicolumn{3}{|c|}{ Model 2} & \multicolumn{3}{|c|}{ Model 3} \\
\hline & Estimate & S.E. & $\mathrm{t}$ & Estimate & S.E. & $\mathrm{t}$ & Estimate & S.E. & $\mathrm{t}$ \\
\hline Intercept & 5.86 & 0.08 & 73.25 & 5.87 & 0.08 & 67.12 & 5.79 & 0.09 & 64.33 \\
\hline Availability of FWPs & 0.13 & 0.06 & $2.17^{*}$ & 0.08 & 0.07 & 1.14 & 0.08 & 0.07 & 1.14 \\
\hline Hindering Work Demands & -0.23 & 0.06 & $-3.83 * * *$ & -0.21 & 0.06 & $-3.50 * * *$ & -0.21 & 0.06 & $-3.50 * * *$ \\
\hline POS & & & & 0.12 & 0.07 & 1.71 & 0.20 & 0.08 & $2.50^{*}$ \\
\hline Flexibility I-deals & & & & 0.10 & 0.06 & 1.67 & 0.12 & 0.06 & $2.00^{*}$ \\
\hline Flexibility I-deals * POS & & & & & & & 0.09 & 0.03 & $3.00 * *$ \\
\hline$-2 \mathrm{LL}$ & 559.06 & & & 550.28 & & & 544.19 & & \\
\hline$\Delta-2 \mathrm{LL}$ & $23.42 * * * a$ & & & $8.78^{*}$ & & & $6.09 *$ & & \\
\hline D.f. & 2 & & & 2 & & & 1 & & \\
\hline Level 1 Intercept Variance and Standard Error & $0.01(0.02)$ & & & $0.01(0.02)$ & & & $0.01(0.02)$ & & \\
\hline Level 2 Intercept Variance Standard Error & $1.24(0.13)$ & & & $1.18(0.12)$ & & & $1.15(0.13)$ & & \\
\hline
\end{tabular}

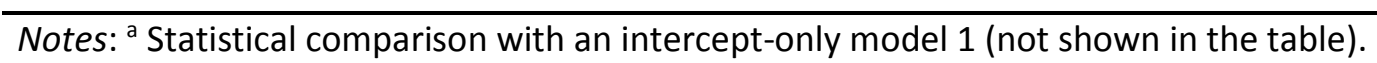

FWPs: Flexible work practices; POS: Perceived organizational support. 
For all values, gamma coefficients, their corresponding standard error and t values are reported.

$n=186$ subordinates; 59 supervisors.

$* \mathrm{p}<0.05 ; * * \mathrm{p}<0.01 ; * * * \mathrm{p}<0.001$. 
Table 4. Moderation analyses results for work performance

\begin{tabular}{|c|c|c|c|c|c|c|c|c|c|}
\hline \multirow[b]{3}{*}{ Variables } & \multicolumn{9}{|c|}{ Work Performance } \\
\hline & \multicolumn{3}{|c|}{ Model 1} & \multicolumn{3}{|c|}{ Model 2} & \multicolumn{3}{|c|}{ Model 3} \\
\hline & Estimate & S.E. & $\mathrm{t}$ & Estimate & S.E. & $\mathrm{t}$ & Estimate & S.E. & $\mathrm{t}$ \\
\hline Intercept & 6.19 & 0.12 & 51.58 & 6.26 & 0.11 & 56.91 & 6.24 & 0.10 & 62.40 \\
\hline Availability of FWPs & 0.03 & 0.05 & 0.61 & 0.01 & 0.04 & 0.25 & 0.02 & 0.06 & 0.33 \\
\hline POS & 0.02 & 0.06 & 0.33 & 0.06 & 0.05 & 1.21 & 0.07 & 0.05 & 1.41 \\
\hline Flexibility I-Deals & 0.05 & 0.03 & 1.67 & 0.05 & 0.03 & 1.67 & 0.05 & 0.03 & 1.67 \\
\hline Hindering Work Demands & & & & -0.02 & 0.03 & -0.67 & -0.01 & 0.06 & -0.16 \\
\hline Family Performance & & & & 0.11 & 0.04 & $2.75^{* *}$ & 0.14 & 0.04 & $3.50 * * *$ \\
\hline Family Performance * Hindering Work Demands & & & & & & & -0.06 & 0.02 & $-3.00 * *$ \\
\hline$-2 L L$ & 360.39 & & & 332.69 & & & 326.47 & & \\
\hline$\Delta-2 \mathrm{LL}$ & $15.21 * * * a$ & & & $27.70 * * *$ & & & $6.22 * *$ & & \\
\hline D.f. & 2 & & & 2 & & & 1 & & \\
\hline Level 1 Intercept Variance and Standard Error & $0.20(0.02)$ & & & $0.20(0.02)$ & & & $0.19(0.02)$ & & \\
\hline Level 2 Intercept Variance Standard Error & $0.74(0.16)$ & & & $0.49(0.11)$ & & & $0.47(0.11)$ & & \\
\hline
\end{tabular}

Notes: a Statistical comparison with an intercept-only model 1 (not shown in the table). 
FWPs: Flexible work practices; POS: Perceived organizational support.

For all values, gamma coefficients, their corresponding standard error and T values are reported.

$n=186$ subordinates; 59 supervisors.

$* \mathrm{p}<0.05 ; * * \mathrm{p}<0.01 ; * * * \mathrm{p}<0.001$. 
Figure 1. Conceptual Model

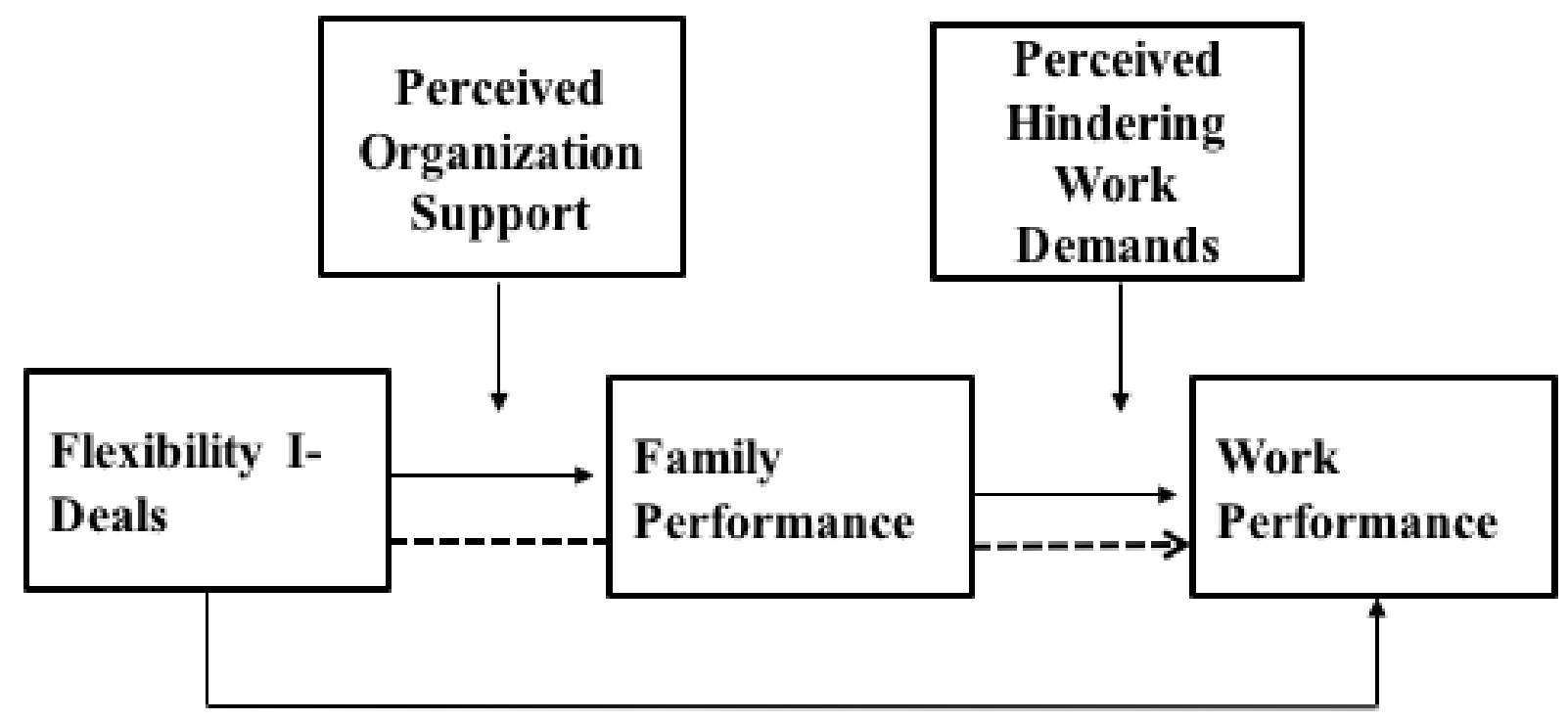

Note. Dotted lines denote the mediation of family performance between flexibility i-deals and work performance. 
Figure 2. Interaction of flexibility i-deals and perceived organization support on family performance

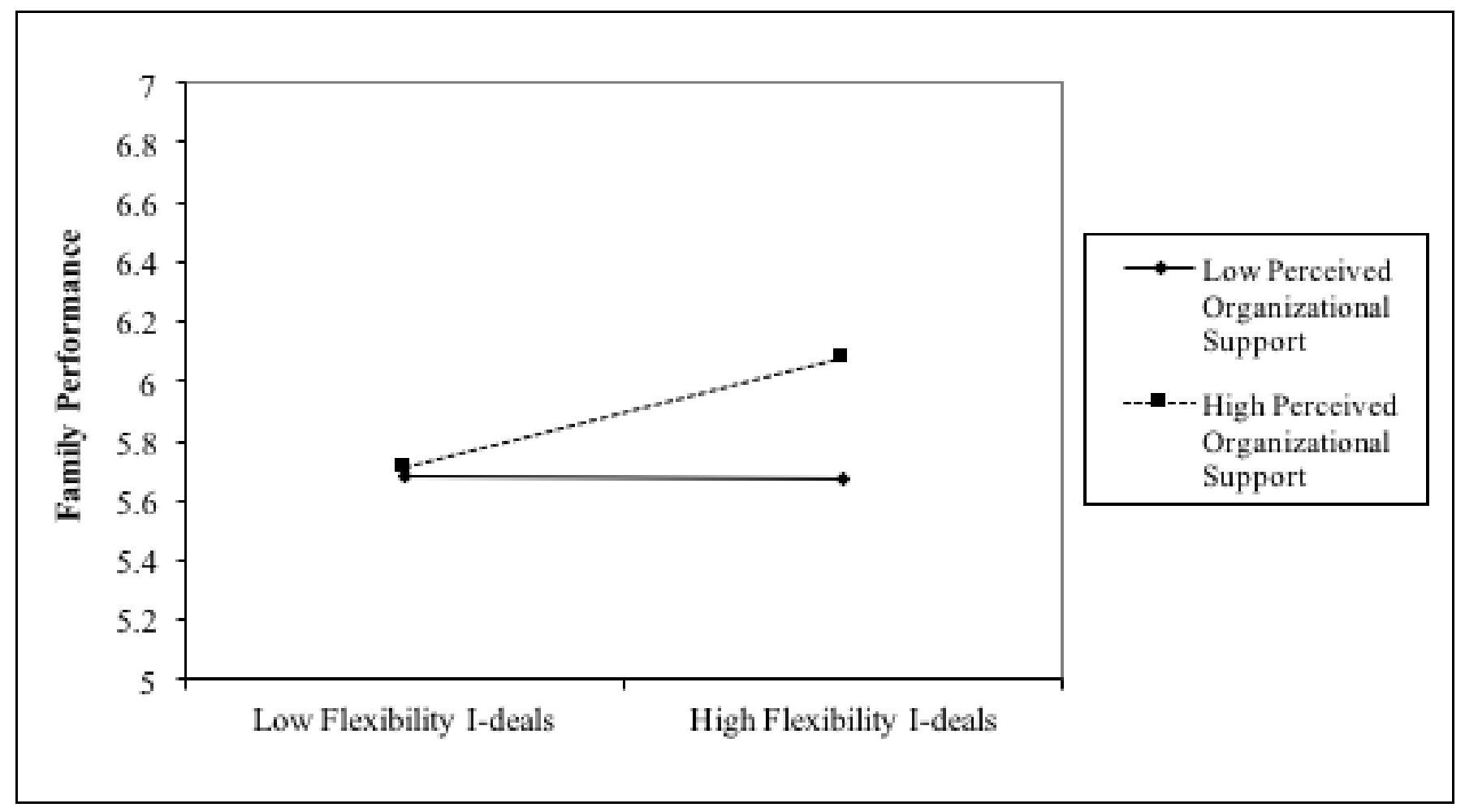


Figure 3. Interaction of family performance and hindering work demands on work performance

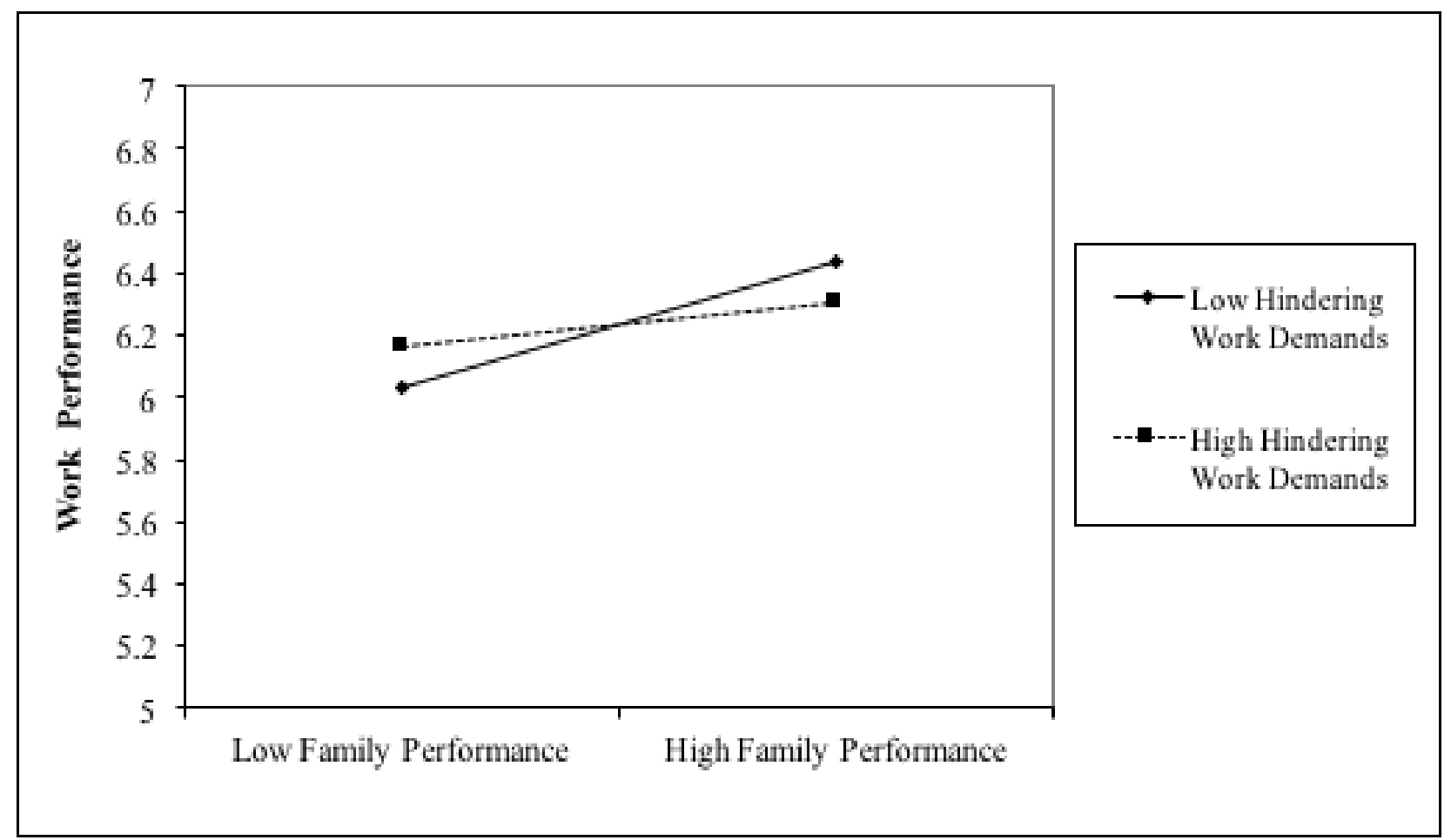

